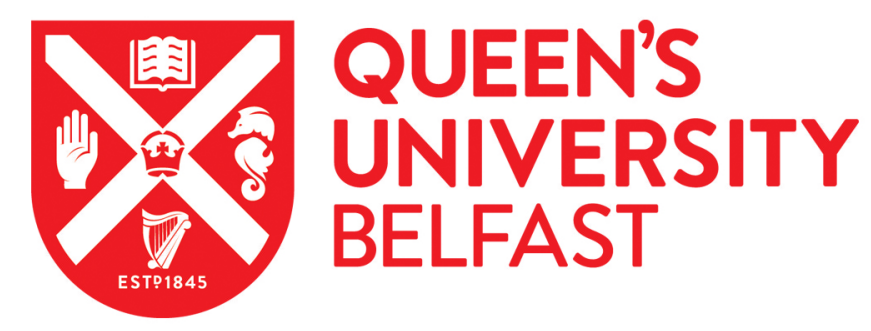

\title{
Adjusting to life after esophagectomy: the experience of survivors and carers
}

McCorry, N., Dempster, M., Clarke, C., \& Doyle, R. (2009). Adjusting to life after esophagectomy: the experience of survivors and carers. Qualitative Health Research, 19(10), 1485-1494.

https://doi.org/10.1177/1049732309348366

Published in:

Qualitative Health Research

Document Version:

Peer reviewed version

Queen's University Belfast - Research Portal:

Link to publication record in Queen's University Belfast Research Portal

Publisher rights

Copyright 2009, the Authors

This work is made available online in accordance with the publisher's policies. Please refer to any applicable terms of use of the publisher.

\section{General rights}

Copyright for the publications made accessible via the Queen's University Belfast Research Portal is retained by the author(s) and / or other copyright owners and it is a condition of accessing these publications that users recognise and abide by the legal requirements associated with these rights.

Take down policy

The Research Portal is Queen's institutional repository that provides access to Queen's research output. Every effort has been made to ensure that content in the Research Portal does not infringe any person's rights, or applicable UK laws. If you discover content in the Research Portal that you believe breaches copyright or violates any law, please contact openaccess@qub.ac.uk. 
Qualitative

Health Research

Adjusting to Life after Esophagectomy: the Experience of Survivors and Carers

\begin{tabular}{|r|l|}
\hline Journal: & Qualitative Health Research \\
\hline Manuscript ID: & QHR-2008-0282.R2 \\
\hline Manuscript Type: & Research Article \\
\hline Keywords: & $\begin{array}{l}\text { cancer, cancer, psychosocial aspects, caregiving, coping and } \\
\text { adaptation, focus groups, survivorship }\end{array}$ \\
\hline
\end{tabular}

\section{(1) ScholaroNE}


Running head: Adjusting to life after esophagectomy

Adjusting to Life after Esophagectomy: the Experience of Survivors and Carers

\author{
Noleen K. McCorry \\ Queen's University Belfast, Belfast, Northern Ireland, United Kingdom \\ Martin Dempster \\ Queen's University Belfast, Belfast, Northern Ireland, United Kingdom \\ Ceara Clarke \\ Northern Health \& Social Care Trust, Antrim, Northern Ireland, United Kingdom \\ Robert Doyle \\ Queen's University Belfast, Belfast, Northern Ireland, United Kingdom
}

Dr Noleen K. McCorry, PhD, School of Psychology, Queen’s University Belfast, Belfast, BT7 1NN, United Kingdom. n.mccorry@qub.ac.uk Tel: +44 2890975650 Fax: +44 2890664144

Dr Martin Dempster, PhD, School of Psychology, Queen's University Belfast, Belfast, BT7 1NN, United Kingdom. m.dempster@qub.ac.uk Tel: +44 2890975547 Fax: +44 2890664144

Dr Ceara Clarke, DClinPsych, CAMHS Team, Northern Health \& Social Care Trust, Massereene House, Station Road, Antrim, Northern Ireland, United Kingdom. cearaclarke@btinternet.com Tel: +442894415700

Mr Robert Doyle, BSc, School of Psychology, Queen's University Belfast, Belfast, BT7 1NN, United Kingdom. robertdoyle84@btinternet.com 


\begin{abstract}
Following surgery for esophageal cancer, patients can experience complex physical, social and emotional changes. Investigation of these challenges, particularly from the perspective of the patient and their carer has been limited. The current study explores the emotional and cognitive experiences of esophageal cancer survivors, and those of their carers using focus groups conducted with members of a patient support group. Analysis of the patients' data yielded 3 themes: coping with a death sentence; adjusting to and accepting an altered self; and the unique benefits of peer support. Analysis of the carers' data also yielded 3 themes: the carer as buffer, representations of recovery and recurrence, and normalizing experiences through peer support. Esophageal cancer patients and their carers require holistic support in their efforts to adjust to the social, emotional and physical consequences of esophagectomy. Peers could be an effective channel for the support of patients and carers.
\end{abstract}

Keywords: cancer; cancer, psychosocial aspects; caregiving; coping and adaptation; focus groups; holistic care; survivorship 
Esophageal cancer is the fifth most common cause of cancer death in the United Kingdom (responsible for around 5\% of all cancer deaths), and rates of esophageal cancer have been increasing over the last 25 years, particularly among men (Cancer Research UK, 2007). Surgery is the standard treatment for esophageal cancer, although $50 \%$ of patients are unfit for surgery at the time of diagnosis (Siewart et al., 2001), and overall five-year survival rates are poor, typically between 5\% and 10\% (Earlam \& Cunha-Melo, 1980; Stockeld et al., 2002).

Most research in this population has focused on mortality and the prevalence of dysphagia (Blazeby, Williams, Brookes, Alderson, \& Farndon 1995; Boyce, 1999; Sagar, Gauperaa, \& Sueling, 1994). There have been several quantitative studies measuring quality of life following surgery (Lindars, 1994; McLarty et al., 1997), but with inconsistent results (perhaps due to problems of response shift, or variations in measurement instruments), and with limited utility for helping to appreciate the survivor's experience following esophagectomy. More recently there have been a few qualitative investigations of specific aspects of the illness from the patients' perspective: Watt and Wyatt (2003) explored the experience of dysphagia from the perspective of the patient; Mills \& Sullivan (2000) described patients' information needs; and Andreassen, Randers, Nasland, Stockeld, and Mattiasson (2006) have explored patients' experiences of living with esophageal cancer and how they seek information. In addition, Wainwright, Donovan, Kavadas, Cramer, and Blazeby (2007) have now highlighted the complex interaction of physiological, psychological and social processes involved in "Remapping the Body" after surgery for esophageal cancer. The current study sought to add to this understanding of the esophageal cancer survivor's experience of their condition following surgery by exploring their cognitive, emotional and social experience of the condition, so that clinicians and researchers might better understand the breadth and depth of challenges negotiated by these patients, and hence tailor their advice, support and intervention to best meet the needs of this patient group. Following evidence from Andreassen et al. (2006), whose participants reported that their partners were more psychologically affected than they were themselves, and increasing evidence that cancer caregivers suffer higher levels of recurrence fears than patients (Mellon, Kershaw, Northouse \& Freeman-Gibb, 2007), we also sought to explore the experience of the patient's partner 
(or primary carer). To date, there has been no published account of the experience of partners or carers of esophageal cancer survivors.

Hence, the current study sought to explore the cognitive and emotional experiences of esophageal cancer survivors, and those of their carers.

\section{Method}

Ethics approval was obtained from the University Ethics Committee. All members of the Oesophageal Patients' Association (OPA) in Northern Ireland were informed (via OPA postal newsletter) that researchers would be attending the next local OPA meeting, and were hoping to facilitate group discussions among survivors and their carers about their experiences of esophageal cancer. It was also stressed in this correspondence that there was no obligation to participate in the research, and that alternative activities would be available for those not wishing to take part in the group discussions. The recruitment of OPA members provided a pragmatic approach to data collection in a population where recruitment is difficult to negotiate - mortality and relapse rates are high, and hence this population is under-represented in this type of research. Although this approach (recruitment from a patients' support group) generates questions about patient characteristics, because patients attending support groups are likely to be more highly educated, to desire more information, and to use more adaptive coping (Grande, Myers, \& Sutton, 2006), it also allows the researcher to explore the role of peer support in the experience of esophageal cancer.

Focus groups were the chosen method of data collection because these provide an efficient means of sensitizing the researcher to salient issues, especially where little is known in the area (Easton, 1999). The discussion-oriented format of focus groups also optimizes interactive dynamics and encourages the articulation of viewpoints, where one participant's comments will prompt others to share their thoughts and experiences. In addition, the focus group (unlike individual interviews) allows the participants to navigate issues (some potentially distressing or sensitive) in a supportive environment of their peers. They are also an effective vehicle for eliciting and understanding the social, cultural, and interpersonal nature of experiences and shared understandings, which will be constructed by participants through their shared discourse. 
At a local OPA meeting a brief presentation was provided by one of the researchers to explain the goals of the research. After a brief interlude and opportunity to question the researchers, those wishing to participate were asked for their written consent. All attendees expressed a desire to participate in the focus group discussions.

Survivors and carers were subsequently separated for the purposes of the group discussions. Group moderators explained the purpose of the discussion to their group, impressing on the group members that the researchers were interested in the participants' experiences and understandings, and a wide range of different points of view. After this introduction participants were asked to give a brief historical account of their experience with esophageal cancer. Following these narratives, a general question was introduced to the group: "Can you tell me how you feel about esophageal cancer?" Although the intention was to explore, as much as possible, the participants' perspectives of their experiences, additional prompts were used when necessary to elicit both cognitive and emotional aspects of their experience. As far as possible, the moderator allowed the discussion to progress, in content and pace, at the preference of the participants. Another member of the research team kept notes, identified the order of speakers for later transcription, and recorded any salient non-verbal responses of participants. At the end of the discussion, the moderator gave a brief summary of what they had learnt from the group and asked for their feedback. The discussions lasted between 60 and 80 minutes. All focus group discussions were audio-taped.

\section{Participants}

In total, 12 survivors (nine male and three female) and 10 carers (eight female and two male) participated in the focus group discussions. The relationships between survivor and carer were: seven husband / wife dyads, two wife / husband dyads, and one mother / daughter dyad. Two male survivors were unaccompanied. Six survivors were aged $56-65$ years, three were aged $66-75$ years, two were aged 76 - 85 years, and one survivor was aged $46-55$ years. All patients had undergone surgery as part of their treatment for esophageal cancer. At the time of participation, time since diagnosis (selfreported) ranged from 14 months to 17 years, and time since surgery ranged from 7 months to 17 years.

\section{Analysis}


Recordings were subsequently transcribed and anonymised. Data was analyzed according to standard thematic analysis techniques (Denzin \& Lincoln, 1998). Descriptive codes of analysis were attached to segments of text, and then reviewed to identify broad categories. All text belonging to the same category was compared (Kuckartz, 1995). The researchers met to discuss, clarify and refine the coding categories. The analysis process also involved a purposeful search for deviant cases and explanations. The categories were further refined through an inductive and iterative process of going back and forth between the text and our developing conceptual framework, culminating with the emergence of three higher order themes from the survivors' data, and three themes from the carers' data.

\section{Results}

Analysis of the survivors' data resulted in the emergence of three themes: coping with a death sentence, adjusting to and accepting an altered self (physical changes, social and emotional changes, and role changes), and the unique benefits of peer support. Analysis of the carers' data yielded three themes: the carer as buffer, representations of recovery and recurrence, and normalizing experiences through peer support.

\section{Survivors}

Coping with a Death Sentence

Participants (without exception) described the immense shock of receiving a diagnosis of esophageal cancer and its poor "reputation". "I thought when the diagnosis was made, it was a death sentence. It really shook me up and I thought semi-seriously about suicide."

Transferring perceived responsibility to others (especially medical professionals) at this stage appeared to help patients to cope with a situation where they could exert little control. This type of denial appears to have helped to protect patients' emotional well-being while they awaited surgery.

When you are first diagnosed it hits you like a 10-tonne hammer hitting you in the chest, but when you think about it, ok you've got cancer, what can I do about it? Nothing. And that's what I said to my cancer specialist. "I don't have the problem, you have the problem, so I'm not going to worry about it. I'm giving it to you, you worry about it." And exactly the same thing with the surgeon. 
Adjusting to and Accepting an Altered Self

Adjusting to and accepting physical changes. Following surgery, the process of recovery was described as a mirror-image of the deterioration observed prior to surgery, especially in relation to weight gain and eating ability.

Every day there was something else that you couldn't get down. Even different liquids.

Suddenly I found even the tea couldn't go down. Then the coffee wouldn't go down and some solids as well . . . I would suddenly have to disappear because maybe a wee sandwich that I knew I could eat the previous day. I just couldn't get it down that day. You had to disappear to get rid of it. It was awkward and I stopped eating in front of anybody, even my wife ... so before the surgery, everyday there was something else you couldn't get down and after the surgery, every day, there was something that you could get down.

Sensory feedback from the body was altered following surgery, and patients described how they had to "learn" appropriate amounts to eat. They were unable to rely on feelings of satiety, often denying themselves food even if they were still feeling hungry.

You can't really eat a lot, but I don't find something telling me that I'm full and if I enjoy something I would say "Is there any more?" But after it is down, that extra [food] I feel as if I want to be sick then, but its only after I've eaten it . . I just find that you have to accept it, and this is how life is going to be from now on. That's the way I look at it.

Well I've got to the stage now where I cut off [eating] at a certain level, because you can find yourself in the bathroom or you find it coming up again, so you try and measure your meal as you go and stop at the right time. It is hard to do.

Adjusting to social and emotional changes. The consequences of patients' altered eating behaviors were felt at an interpersonal and social level. Especially in the early period following surgery when survivors described how they had less control over the body's reactions to eating (such 
as choking and vomiting), patients withdrew from the company of their family and friends. They were often embarrassed and nervous about eating in public places, and some described a perceived stigma associated with these altered eating behaviors (such as ordering small portion sizes and children's meals). "You feel so embarrassed, and you are eating a wee corner of your meal, and the waiter says 'Is there something wrong with that?'” Patients also described emotional struggles, and the "fear of the unknown".

When you have the operation it changes your life ... It changes you mentally and I feel that eh ... somewhere along the line I think a psychologist could talk to you and ease your worries, because we all know doubt ... you don't know when you'll be getting measured for the coffin.

Although fear of recurrence appeared to be a significant concern for all patients, many chose to focus on gaining some control over their situation, or maintaining a positive outlook about their health.

It's the fear of the unknown. If I get it again there's nowhere else to go, but . . . there's more chance of getting knocked down by a bus ... I had my surgery five and a half years ago and I keep very active, and eh, I think its part of the cure.

Adjusting to role changes. Finding a new focus, and disciplining the self not to give in to negativity was stressed by patients as an important goal of adjustment post-surgery, especially when faced with role and identity challenges, such as being unable to return to work or altered familial roles. The following quote describes a patient's daily struggle after being "pensioned off".

You get up some mornings and you don't feel like doing anything. Those are the mornings that you really say to yourself "right - start such and such, because if you get started you keep going" ... having something to do and something to think about is the best medicine of the whole lot.

The Unique Benefits of Peer Support 


\section{Carers}

Patients described the informational and practical support received from medical staff, and also highlighted the role of "being known" by their physician throughout their experience. They advocated the unique benefits for psychological well-being and hope provided by peer example and support, particularly the role of the support group. The following quote helps to demonstrate the processes of upward social comparison at work within the group.

I think that one of the things that helped me was whenever I was in touch with Ben [member of support group] after the operation ... and he wasn't there because he was on holiday in Australia, and I thought - oh there is life after this. And that actually helped me a lot.

Although most patients did not have contact with other survivors until they made contact with the support group (generally following their recovery from surgery), they still appreciated a role for peer example and support within the healthcare setting, both in preparation for, and following surgery. A few patients had (informally) met patients who had undergone surgery, and described the influences of this on their attitudes and behavior.

The day I was actually diagnosed and they told me I needed to have an operation. And there was a lady in that day who had come in to get a check-up and she had had the operation ... six weeks ago. And me meeting that woman made my mind up for me - I'm going for the operation straight away.

\section{The Carer as Buffer}

Carers described their responsibility for protecting the patient and their family from distress, sometimes by choosing to withhold information from them, and needing to be strong for those around them. This however, appeared to contribute to the carer's feelings of isolation, at a time when they were clearly suffering from elevated levels of distress themselves, often resulting in altered sleeping and eating patterns and reduced self-care of their own health problems.

He wasn't aware of the severity of the operation. And also, he doesn't know himself that he hemorrhaged after the operation and that night they had to bring him back to stop the 
hemorrhage, they opened him, I think they said his lungs were full of blood. They also told me that if he hadn't had the operation, if they hadn't got him back to surgery that night it would have been too late ... he is not aware of that, as a matter of fact nobody else in the family is aware of that because I think a secret's best kept if you really keep it to yourself.

I felt em, I had to be strong for the whole family because I would be a strong person anyway, but they were all looking to me and I couldn't let the side down. And I had nobody to talk to. I was nursing my father with cancer, my sister had just died, I had cancer, John had cancer. There was just nobody. I couldn't let myself down, my guard down and I found the isolation terrible.

Carers felt the burden of responsibility for the patient's recovery. One woman described herself as her husband's "whipping boy", as she relentlessly tried to encourage her husband to eat, and to take medication.

You were trying to get him to eat, trying to get him to take his tablets and I was getting the brunt of everything. And that was the worst ... and it was so hard you know, and I used to have to go out of the room because I started crying.

The carer was also a conduit who provided explanations to family and friends, and in social situations. The following quote is an account of a husband's private conversation with a waiter in a restaurant.

I had to take the guy away to the side and I says "look, would you mind coming back and removing the plate and not saying anything because" - well, I told him the situation.

\section{Representations of Recovery and Recurrence}

Carers appeared to engage in an anxious process of tracking the patient's recovery and health in terms of their ability to eat, their meal sizes, and weight gain. Their discussion was permeated throughout with accounts of this. While patients on the one hand, recognized and accepted that 
smaller portion sizes were a more or less inevitable consequence of surgery, carers' representations of food and eating were heavily emotionally laden and they still represented recovery in terms of the ability to eat larger quantities. "I can't get Bernard out of the small meals ... I have to ring him every day from work to tell him to eat but his eating has got a bit better and he's put on a bit of weight."

Carers were vigilant in their observation of patients "progress", and often interpreted even slight weight loss, dumping, or feeling unwell as indicators of disease recurrence. "Every time that he would not feel well or would have the dumping syndrome, I keep wondering is it back?"

This was clearly a significant source of distress for the carer, permeating their daily thoughts, and felt very keenly when attending for check-ups.

I continually worry about him, he's never out of my mind. He's the first thing on my mind in the morning and the last thing at night - "Have you got pain? Where's the pain?" ... I used to just look for a reaction from their faces, just to see is he doing a bit better, is he not? ... If there's a slight smile it gave you hope. You know, I was very aware of people's reactions in the hospital around me.

\section{Normalizing Experiences through Peer Support}

Carers described varied experiences of support from health professionals, but recognized the value of peer support, especially for normalization of experiences (such as eating habits / ability), reducing feelings of isolation, and as a source of hope.

Carers are supposed to forage for information, you know - am I doing the right thing? You know he's not eating right, I can't get him to eat and it was only when I came here that I started talking to people ... the first lifeline we had was here [the support group] ... it was just like a breath of fresh air . . . and things that Brian had, this dumping syndrome, he wasn't the only one ... My friends were good but I think they cared about us so much, they couldn't ask, they didn't want to, they just wanted life to go on.

\section{Discussion}


The research literature addressing the psychosocial aspects of cancer continues to expand, with patient narratives occupying a prominent position due to growing appreciation of their relevance in identifying and meeting the needs of those affected by cancer, particularly in the development of services (Cristancho, Garces, Peters, \& Mueller, 2008; Lende \& Lachiondo, 2009), addressing the burden of illness (Ching, Martinson, \& Wong, 2009; Kelly, 2009; Tritter \& Calnan, 2002), as well as understanding professional, cultural, and societal responses to cancer (Crouch \& McKenzie, 2000; Kaiser, 2008; Mathieson \& Stam, 1995). Research demonstrates that patients diagnosed with various forms of cancer are united by their common experience of a potentially life-threatening disease (Briebart \& Holland, 1988; Crouch \& McKenzie, 2000; Mathieson \& Stam, 1995), bodily disruption (Mathieson \& Stam, 1995; Wainwright et al., 2007), threats to their identity (Bellizzi \& Blank, 2007; Gillies \& Johnston, 2004; Mathieson \& Stam, 1995), fear of recurrence (Allen, Savadatti, \& Gurmankin Levy, 2009; Crouch \& McKenzie, 2000; Gray et al., 1998; Oxlad, Wade, Hallsworth, \& Koczwara et al., 2008) and often perceptions of stigma or isolation (Grahn \& Danielson, 1996; Mathieson \& Stam, 1995) - themes which were all exemplified by our participants. However, Vickery, Latchford, Hewison, Bellew and Feber (2003) suggest that particular cancers appear to have a unique presentation of difficulties. Investigation of patient (and carer) experience among our participants reveals how these common themes are contextualized for esophageal cancer survivors and their carers, and the dual psychosocial challenges of both the cancer and its treatment.

Both survivors and their carers described how their initial cognitions about esophageal cancer (upon diagnosis) were of very severe consequences. Indeed, many described how they were surprised at the possibility of treatment. These illness representations are formed by social experience (for example, many participants mentioned the experience of the actor John Thaw) and previous knowledge about the disease. Certainly esophageal cancer has a relatively poor prognosis, but the success of treatment for esophageal cancer is very dependent upon the stage at which the patient presents for diagnosis. It is therefore imperative that patients are aware that treatment can be successful, and that they (and their GPs) act quickly in response to symptoms, recognizing the importance of urgency in seeking specialist advice. The relationships between such illness representations and responses to illness are modeled by Leventhal's Self-Regulatory Model 
(Leventhal, Meyer, \& Nerenz, 1980; Leventhal, Nerenz, \& Steele, 1984), and the importance of illness and treatment representations for influencing behaviors, such as the decision to engage in early screening, attendance for treatment, and lifestyle changes has already been demonstrated for other illnesses (Bowen et al., 2003; Orbell, Hagger, Brown, \& Tidy, 2006; Rabin \& Pinto, 2006; Ross, Walker, \& MacLeod, 2004). Given that esophageal cancer is the fastest growing cancer in terms of prevalence in the United Kingdom, these illness and treatment representations, and their influence on care-seeking behavior deserve further exploration, if mortality is to be reduced.

A diagnosis of cancer can be a traumatic experience, and denial is not an uncommon response to such a diagnosis (Vos \& Haes, 2007), especially where patients have such poor representations of the severity and consequences of the disease. Evidence from the current study suggests that coping through denial, avoidance and transfer of responsibility following diagnosis (while patients awaited surgery) might have helped to protect the patient's psychological well-being in the short term. However, it is unclear how these coping strategies and avoidance of emotional processing might contribute to post-trauma symptomatology following surgery, or how successfully the patient can regain control following surgery and begin to use more problem-focused strategies for successful adjustment. In a study of predictors of adjustment in breast cancer Stanton, Danoff-Burg, and Huggins (2002) reported that avoidance during the pre-operative period was related to higher distress at three months post surgery, but a relationship could not be detected at one year. We must therefore also consider individual and gender preferences for informational and emotional processing at this early stage.

Wainwright et al. (2007) describe in detail the process of "Remapping the body" and "learning" to eat again after surgery for esophageal cancer. The current study has produced similar findings to theirs in terms of the representations and meanings associated with weight gain and eating ability, and the process of "learning" to eat again. Patients are unable to conform to the social norms of eating behavior (Caldwell \& Watson, 2004) as they struggle to control their bodily responses, resulting in consequences for interpersonal and social relations. Our participants also described the negotiation of role changes. For some participants this meant the inability to work, or the loss of caring or professional responsibilities, which can have a profound effect on self-esteem and perceived 
worth. Participants also described existential concerns (also highlighted by Andreassen et al., 2006), particularly related to a fear of recurrence of the disease. Wainwright et al. suggest that this process of physical and social adjustment following surgery is akin to learning to walk again following amputation, yet little support or intervention exists within the healthcare system for esophagectomy patients in the United Kingdom. Our study also highlights the need for ongoing support of these patients (and their carers) as they adjust to physical, social and emotional changes following surgery. As suggested by Wainwright et al. it is difficult to separate physiological and social consequences of surgery, and rehabilitation could be most effective if considered as a patient-centered and holistic initiative.

These physical, social and psychological adaptations align the experience of esophageal cancer following surgery with other chronic illnesses, where long-term adaptation and re-negotiation of identity is required, and where the patient experiences constant burden, continual management, and concerns about future health (Kaiser, 2008; Mathieson \& Stam, 1995). However, the definition of cancer as a chronic illness is a matter of debate, with some authors (Tritter \& Calnan, 2002) arguing that this characterization does cancer a disservice since it does not distinguish the complexity of cancer treatment from the majority of chronic illnesses, or the acute episodes associated with the disease. Cancer patients themselves can have very different representations of chronicity, for example men with prostate cancer are more likely to describe themselves as "someone who has had cancer" (Bellizzi \& Blank, 2007), whereas women previously diagnosed with breast cancer prefer to describe themselves as "living with chronic illness" (Oxlad et al., 2008). For esophageal patients, there appears to be an initial acute period (prior to, and following surgery) where intensive support and preparation would be beneficial for patients, accompanied by an appreciation of the longer term consequences of the cancer and its treatment, fears of recurrence, and for some patients, episodic periods of additional treatment (such as esophageal stretching procedures).

Although it is well recognized that cancer affects not only the patient / survivor, but the quality of life and psychological well-being of family members (Kim \& Given, 2008; Mellon, Northouse, \& Weiss, 2006; Yang \& Lee, 2008), no existing research has described the experience of carers of esophageal cancer survivors. Evidence from the current study suggests that carers might act 
as a buffer or intermediary between the patient and other members of the family, friends and healthcare professionals, providing explanations in social situations and attempting to protect the emotional well-being of the patient. This pattern is evident in other cancers, and particularly among female carers (Bottorff et al., 2008; Heyman \& Rosner, 1996). Carers provide practical and emotional support to the patient, often alongside other caring roles and their own personal health problems, and tend to feel the weight of responsibility for the patient's recovery process. The majority of carers in the present study were female (reflecting the greater prevalence of esophageal cancer in males) who are in general more emotionally expressive than males, report greater anxiety, and are more likely to adopt care-giver roles. These female characteristics have implications for the composition of support groups and their group dynamics, and could be critical to their effectiveness, even for male cancers such as prostate cancer (Bottorff et al., 2008). The presence of female carers might also provide important benefits for female survivors of esophageal cancer, who could otherwise feel marginalized by male styles of coping and communication within support groups. Further investigation of the dynamics and effectiveness of unisex support groups for both men (including single men) and women is warranted.

Several studies have described greater fears of recurrence or worry among family caregivers than among patients themselves (Harrison, Haddad, \& Maguire, 1995; Matthews, 2003), and Harrison et al. suggest that this might be attributed to greater pre-occupation with the day-to-day aspects of the illness among patients themselves, hence distracting them from long-range concerns about the illness. Although misinterpretation of neutral bodily symptoms has been described among cancer patients themselves (Lasry \& Margolese, 1992; LeeJones, Humphris, Dixon, \& Hatcher, 1997), carers in the current study were vigilant observers of the patient's progress, and communicated a level of anxious pre-occupation with daily perceived signs and symptoms. Often, normal symptoms resulting from the consequences of surgery were interpreted as symptoms of disease recurrence. For example, there appears to be some incongruence between patients' and carers' representations of eating - whereas patients appeared to have accepted that they could not eat as much as they did prior to surgery, and that "dumping" (a syndrome which happens as a result of surgery when the lower end of the small intestine fills too quickly with undigested food from the stomach) was a consequence of their surgery, 
carers described how they sought to increase the patient's meal-size to pre-disease levels, as an indication of more successful recovery, and interpreted dumping as indicative of disease recurrence. It is possible that because of physiological feedback from their own bodily processes patients might have a greater sense of coherence about their condition than carers. In contrast, carers' memories of pre-surgery disease-related symptoms impacts on their representations of future somatic stimuli, and might shape their emotional responses. Future research could explore how best to promote greater congruence between carer and patient representations of the condition, and how to reduce the emotional impact of recurrence fears within both groups. Carers in particular might be less likely to express their fears fully to the patient or their family because of the wish to protect the emotional well-being of others, therefore adding to their burden and feelings of isolation.

One area of clear congruence between carers and patients was in their appreciation of the benefits of peer support. The benefits of peer support programs for improving satisfaction, increasing social support and improving mood among cancer patients has been well documented, although there is also evidence of some adverse outcomes, and a general paucity of well-designed studies (for a review see Hoey, Ieropoli, White, \& Jefford, 2008). In addition, most research has been conducted among breast cancer populations where there is a relative abundance of both peer and professional support. It is possible that peer support programs could be particularly beneficial for other groups of cancer patients where there is generally less support available (Hoey et al. 2008), such as esophageal cancer. For survivors in the current study, contact with other patients who had "lived experience" of esophageal cancer and esophagectomy had unique benefits, which could not be realized through contact with health professionals or family. Normalization of experiences, opportunities for upward social comparison (Taylor \& Lobel, 1989), and the creation of hope were particularly important for both survivors and carers. Evidence from our survivors suggests that there might also be advantages to a more formalized peer role within the healthcare system. Peers have a unique ability to describe and empathize about the sensory, physical, social and emotional consequences of surgery, hence helping to aid post-operative recovery and wellbeing. Contact with peers might also facilitate positive changes in illness and treatment beliefs, influencing decisions about treatment, and improving wellbeing. Mills \& Sullivan (2000) were positive about other patients as a source of information, but also 
noted the need for care in the implementation of peer advice, as not all encounters with other patients were beneficial.

\section{Limitations and Contributions}

Although the support group environment has many advantages for conducting research in potentially sensitive areas, group composition and dynamics could lead to less then candid accounts of negative experiences, or reluctance to describe accounts which are at odds with other patients' experiences. The context might also have led to greater cognizance of the role and benefits of peers in general. In addition, patients attending support groups are likely to be more highly educated, to desire more information, and to use more adaptive coping (Grande et al., 2006). Future enquiry might usefully be directed at research samples with different patient characteristics.

The current approach has contextualized the complex psychosocial challenges faced by esophageal cancer survivors and their carers. It is also clear that some areas require further exploration and reflection, such as the potential role of peers within the healthcare system for esophageal cancer patients, and the best ways of meeting the complex and interrelated physical, social and psychological rehabilitation needs of patients.

\section{Conclusions}

Both patients and their carers require support and rehabilitation as they negotiate significant physical, social, and emotional challenges post-surgery, including psychological intervention to promote effective coping strategies, and to reduce the impact of fear of recurrence. As evidence continues to mount that illness and treatment representations are related to various illness behaviors, coping, and psychological wellbeing, an assessment of these representations among esophageal cancer survivors and their carers, and their relationship with these outcomes is warranted. Leventhal's SelfRegulatory Model (Leventhal, Meyer, \& Nerenz, 1980; Leventhal, Nerenz, \& Steele, 1984) is a useful framework for modeling these processes of adjustment to illness, and has been applied to many other illnesses such as diabetes and asthma (McAndrew et al., 2008), myocardial infarction (Petrie, Cameron, Ellis, Buick, \& Weinman, 2002), and inflammatory bowel disease (Dorrian, Dempster, \& Adair, 2008) to name but a few. In addition the congruence between patient and carer representations, and their relationship with these outcomes might be explored. Peers could be an effective channel for 
altering illness and treatment representations, with potentially positive effects on coping, illness behaviors, decision making, and wellbeing. 
Allen, D. A., Savadatti, S., \& Gurmankin Levy, A. (2009). The transition from breast cancer 'patient' to 'survivor'. Psycho-Oncology, 18, 71-78.

Andreassen, S., Randers, I., Näsland, E., Stockeld, D., \& Mattiasson, A-C. (2006). Patients' experiences of living with oesophageal cancer. Journal of Clinical Nursing, 15, 685-695.

Bellizzi, K. M., \& Blank, T. O. (2007). Cancer-related identity and positive affect in survivors of prostate cancer. Journal of Cancer Survivorship, 1, 44-48.

Blazeby, J. M., Williams, M. H., Brookes, S. T., Alderson, D., \& Farndon, J. R. (1995). Quality-oflife measurement in patients with esophageal cancer. Gut, 37, 505- 508.

Bowen, D. J., Helmes, A., Powers, D., Andersen, M. R., Burke, W., McTiernan, A. \& Durfy, S. (2003). Predicting breast cancer screening intentions and behavior with emotion and cognition. Journal of Social and Clinical Psychology, 22, 213-232.

Bottoff, J. L., Oliffe, J. L., Halpin, M., Phillips, M., McLean, G. \& Mroz, L. (2008). Women and prostate cancer support groups: the gender connect? Social Science \& Medicine, 66, 1217-1227.

Boyce, H. (1999). Palliation of dysphagia of oesophageal cancer by endoscopic lumen restoration techniques. Cancer Control, 6, 73-83.

Briebart, W. \& Holland, J. C. (1988). Psychosocial aspects of head and neck cancer. Seminars in Oncology, 15, 61-69.

Caldwell, M., \& Watson, J. L. (Eds.). (2004). The cultural politics of food and eating. London: Blackwell.

Cancer Research UK. (2007). UK Oesopahgeal Cancer Incidence Rates. Retrieved July 9, 2008, from $\underline{\text { http://info.cancerresearchuk.org/cancerstats/types/oesophagus }}$

Ching, S. S. Y., Martinson, I. M., \& Wong, T. K. S. (2009). Reframing: psychological adjustment of Chinese women at the beginning of the breast cancer experience. Qualitative Health Research, $19,339-351$

Cristancho, S., Garces, D. M., Peters, K. E., \& Mueller, B.C. (2008). Listening to rural Hispanic immigrants in the Midwest: A community-based participatory assessment of major barriers to health care access and use. Qualitative Health Research, 18, 633-646. 
Crouch, M., \& McKenzie, H. (2000). Social realities of loss and suffering following mastectomy. Health, 4, 196-215.

Denzin, N. K., \& Lincoln, Y. S. (Eds.). (1998). Strategies of Qualitative Inquiry. London: Sage.

Dorrian, A., Dempster, M., \& Adair, P. (2008). Adjustment to inflammatory bowel disease: the relative influence of illness perceptions and coping. Inflammatory Bowel Diseases. Retrieved July 212008 from: http://www3.interscience.wiley.com/journal/120775694/abstractDOI: 10.1002/ibd.20583.

Earlam, R., \& Cunha-Melo, J. R. (1980). Esophageal squamoscell carcinoma I: a critical review of surgery. British Journal of Surgery, 67, 381-390.

Easton, K. (1999). Using focus groups in rehabilitation nursing. Rehabilitation Nursing, 24, 212-215.

Gillies, B., \& Johnston, G. (2004). Identity loss and maintenance: commonality of experience in cancer and dementia. European Journal of Cancer Care, 13, 436-442.

Grahn, G. \& Danielson, M. (1996). Coping with cancer experience. II. Evaluating an education and support programme for cancer patients and their significant others. European Journal of Cancer Care, 5, 182-187.

Grande, G. E., Myers, L. B., \& Sutton, S. R. (2006). How do patients who participate in cancer support groups differ from those who do not? Psycho-oncology, 15, 321-334.

Gray, R., Fitch, M., Greenberg, M., Hampson, A., Doherty, M., \& Labrecque, M. (1998). The information needs of well, longer-term survivors of breast cancer. Patient Education \& Counseling, 33, 245-455.

Harrison, J., Haddad, P., \& Maguire, P. (1995). The impact of cancer on key relatives: a comparison of relative and patient concerns. European Journal of Cancer, 31A, 1736-1740.

Heyman, E. N. \& Rosner, T. T. (1996). Prostate cancer: an intimate view from patients and wives. Urological Nursing, 16(2), 37-44.

Hoey, L. M., Ieropoli, S. A., White, V. M., \& Jefford, M. (2008). Systematic review of peer-support programs for people with cancer. Patient Education and Counseling, 70, 315-337.

Kaiser, K. (2008). The meaning of the survivor identity for women with breast cancer. Social Science and Medicine, 67, 79-87. 
Kelly, D. (2009). Changed men: The embodied impact of prostate cancer. Qualitative Health Research, 19, 151-163.

Kim, Y., \& Given, B. A. (2008). Quality of life of family caregivers of cancer survivors - Across the trajectory of the illness. Cancer, 112, 2556-2568.

Kuckartz, U. (1995). Case-oriented quantification. In U. Kelle (Ed.), Computer aided qualitative data analysis (pp. 158-166). London: Sage.

Lasry, J. C. M., \& Margolese, R. G. (1992). Fear of recurrence, breast-conserving surgery, and the trade-off hypothesis. Cancer, 69, 2111-2115.

Lee-Jones, C., Humphris, G., Dixon, R., \& Hatcher, M. B. (1997). Fear of cancer recurrence - a literature review and proposed cognitive formulation to explain exacerbation of recurrence fears. Psycho-oncology, 6, 95-105.

Lende, D. H. \& Lachiondo, A. (2009). Embodiment and breast cancer among African American women. Qualitative Health Research, 19, 216-228.

Leventhal, H., Meyer, D., \& Nerenz, D. (1980). The common sense representation of illness danger. In S. Rachman (Ed.), Contributions to Medical Psychology, Vol. 2, (pp. 7-30). New York: Pergamon Press.

Leventhal, H., Nerenz, D., \& Steele, D. J. (1984). Illness representations and coping with health threats. In A. Baum, S. E. Taylor, \& D. J. Steele (Eds.), Handbook of Psychology and Health: Social psychological aspects of health, Vol. 4, (pp.219-252). Hillsdale, NJ: Erlbaum.

Lindars, J. (1994). Quality of life of patients with oesophageal carcinoma. Nursing Times, 90, 31-32.

Mathieson, C. M., \& Stam, H. J. (1995). Renegotiating identity: cancer narratives. Sociology of Health \& Illness, 17, 283-306.

McAndrew, L. M., Musumeci-Szabo, T. J., Mora, P. A., Vileikyte, L., Burns, E., et al. (2008). Using the common sense model to design interventions for the prevention and management of chronic illness threats: from description to process. British Journal of Health Psychology, 13, 195-204.

McLarty, A. J., Deschamps, C., Trastek, V. F., Allen, M. S., Pairolero, P. C., \& Harmsen, W. S. (1997). Esophageal resection for cancer of the esophagus: long-term function and quality of life. Annals of Thoracic Surgery, 63, 1568-1572. 
Mellon, S., Kershaw, T. S., Northouse, L. L., \& Freeman-Gibb, L. (2007). A family-based model to predict fear of recurrence for cancer survivors and their caregivers. Psycho-oncology, 16, 214223.

Mellon, S., Northouse, L. L., \& Weiss, L. K. (2006). A population-based study of the quality of life of cancer survivors and their family caregivers. Cancer Nursing, 29, 120-131.

Mills, M. E., \& Sullivan, K. (2000). Patients with operable oesophageal cancer: their experience of information-giving in a regional thoracic unit. Journal of Clinical Nursing, 9, 236-246.

Orbell, S., Hagger, M., Brown, V., \& Tidy, J. (2006). Comparing two theories of health behavior: A prospective study of noncompletion of treatment following cervical cancer screening. Health Psychology, 25, 604-615.

Oxlad, M., Wade, T. D., Hallsworth, L., \& Koczwara, B. (2008). 'I'm living with a chronic illness, not ... dying with cancer': a qualitative study of Australian women's self-identified concerns and needs following primary treatment for breast cancer. European Journal of Cancer Care, 17, 157166.

Petrie, K. J., Cameron, L. D., Ellis, C. J., Buick, D., \& Weinman, J. (2002). Changing illness perceptions following myocardial infarction: An early intervention, randomized controlled trial. Psychosomatic Medicine, 64, 580-586.

Rabin, C., \& Pinto, B. (2006). Cancer-related beliefs and health behavior change among breast cancer survivors and their first-degree relatives. Psycho-oncology, 15, 701-712.

Ross, S., Walker, A., \& MacLeod, M. J. (2004). Patient compliance in hypertension: role of illness perceptions and treatment beliefs. Journal of Human Hypertension, 18, 607-613.

Sagar, P. M., Gauperaa, T., \& Sueling, H. (1994). An audit of the treatment of cancer of the esophagus. Gut, 35, 941-945.

Siewart, J. R., Stein, H. J., Feith, M., Bruecher, B. L., Bartels, H., \& Fink, U. (2001). Histological tumor type is an independent prognostic parameter in esophageal cancer: lessons from more than 1,000 consecutive resections at a single center in the western world. Annals of Surgery, 234, 360369. 
Stanton, A. L., Danoff-Burg, S., \& Huggins, M. E. (2002). The first year after breast cancer diagnosis: hope and coping as predictors of adjustment. Psycho-oncology, 11, 93-102.

Stockeld, D., Tennvall, J., Wagenius, G., Albertsson, M., Backman, L., Brodin, O. et al. (2001). A Swedish study of chemoradiation in squamous cell carcinoma of the esophagus. Acta Oncologica, $40,566-573$.

Taylor, S. E., \& Lobel, M. (1989). Social comparison activity under threat - downward evaluation and upward contacts. Psychological Review, 96, 569-575.

Tritter, J. Q., \& Calnan, M. (2002). Cancer as a chronic illness? Reconsidering categorization and exploring experience. European Journal of Cancer Care, 11, 161-165.

Vickery. L. E., Latchford, G., Hewison, J., Bellew, M., \& Feber, T. (2003). The impact of head and neck cancer and facial disfigurement on the quality of life of patients and their partners. Head \& Neck, 25, 289-296.

Wainwright, D., Donovan, J. L., Kavadas, V., Cramer, H., \& Blazeby, J. M. (2007). Remapping the body: learning to eat again after surgery for esophageal cancer. Qualitative Health Research, 17, $759-771$.

Watt, E., \& Wyatt, M. N. (2003). The experience of dysphagia and its effect on the quality of life of patients with oesophageal cancer. European Journal of Cancer Care, 12, 183-193.

Yang, H. J., \& Lee, W. H. (2008). A study of influencing factors on quality of life of family caregivers of patients with lung cancer. Oncology Nursing Forum, 35, 521.

Vos, M. S., \& Haes, J. C. J. M. D. (2007). Denial in cancer patients, an explorative review. PsychoOncology, 16, 12-25.

Noleen K. McCorry, PhD, is a lecturer in Health Psychology at the Queen's University of Belfast, and South Eastern Health and Social Care Trust in Belfast, Northern Ireland, United Kingdom.

Martin Dempster, $\mathrm{PhD}$, is a lecturer in Health Psychology and research co-ordinator for the Doctorate in Clinical Psychology Program at the Queen's University of Belfast, Northern Ireland, United Kingdom. 
Ceara Clarke, DClinPsych, is a Clinical Psychologist with the Child and Adolescent Mental Health Service, Northern Health \& Social Care Trust, Northern Ireland, United Kingdom.

Robert Doyle, BSc, is a recent graduate of the School of Psychology, Queen's University Belfast, Belfast, Northern Ireland, United Kingdom. 